\title{
Abdominal Soft Tissue Necrotic Lesion
}

National Cancer Institute

\section{Source}

National Cancer Institute. Abdominal Soft Tissue Necrotic Lesion. NCI Thesaurus. Code C78165.

A necrotic process occurring in the soft tissues of the abdominal wall. 